\title{
O cuidado em saúde mental: narrativas de familiares de ouvidores de vozes
}

\author{
Priscilla dos Santos da Silva ${ }^{a *}$ (1) \\ Rita de Cássia Maciazeki-Gomes ${ }^{b}$ (i) \\ Maria Laura de Oliveira Couto ${ }^{\mathrm{a}}$ (B) \\ Alice Monte Negro de Paivab (i) \\ Carolina Siomionki Gramajob ${ }^{\text {(1) }}$ \\ Luciane Prado Kantorski ${ }^{a}$ (i) \\ ${ }^{a}$ Universidade Federal de Pelotas, Rio Grande, RS, Brasil \\ b Universidade Federal do Rio Grande, Rio Grande, RS, Brasil
}

\begin{abstract}
Resumo: Ancorado numa perspectiva psicossocial, frente aos desafios da reinserção social e da composição de estratégias de cuidado em liberdade, este estudo tem por objetivo analisar as narrativas dos familiares de ouvidores de vozes sobre suas experiências como cuidadores. Foram realizadas entrevistas narrativas com familiares de participantes de um grupo de ouvidores de vozes em um Centro de Atenção Psicossocial (Caps) da cidade de Pelotas, no Rio Grande do Sul, Brasil. A partir da análise temática, produziram-se três eixos temáticos: (1) experiência de ouvir vozes e necessidade de cuidado; (1) família: práticas de cuidado; e (3) estratégias terapêuticas: tecendo redes de cuidado compartilhadas em saúde mental. As narrativas dos cuidadores reportam dificuldades na convivência com familiares que ouvem vozes, sobrecarga de trabalho relacionada ao cuidado e desafios enfrentados no cotidiano. Destaca-se a importância de espaços grupais de ajuda mútua que possam auxiliar os cuidadores.
\end{abstract}

Palavras-chave: família, cuidadores, ouvidores de vozes, saúde mental.

\section{Introdução}

A Reforma Psiquiátrica no Brasil trouxe novos olhares para o cuidado em saúde mental, com tratamentos mais humanizados e o redirecionamento do modelo assistencial em saúde mental por meio da implementação da Lei no 10.216 (2001). Os Centros de Atenção Psicossocial (Caps), regulamentados pela Portaria $n^{\circ} 336(2002)$, passam a trabalhar no atendimento às pessoas com transtornos mentais graves e persistentes, com enfoque na reabilitação psicossocial (Mota \& Costa, 2017), sendo responsáveis por promover uma articulação social e intersetorial, ampliando suas ações para além da instituição (Delfini, Sato, Antoneli, \& Guimarães, 2009).

Os Caps trabalham com uma equipe multiprofissional que realiza atendimentos em grupos e individuais, além de propostas de intervenções diversificadas, como oficinas terapêuticas, práticas de educação física, arteterapia, entre outras (Mielke, 2009). A produção do cuidado passa a envolver a participação dos próprios sujeitos em sofrimento, sua família e a comunidade. Essas estratégias são importantes para romper com o paradigma do modelo hospitalocêntrico (Kantorski \& Andrade, 2017). Porém, Pereira, Reinaldo e Andrade (2015) apresentam uma discussão a respeito da formação profissional direcionada a esse modelo de

* Endereço para correspondência: priscillaaass@gmail.com cuidado. Os autores afirmam que esse processo, que teve início com a Reforma Psiquiátrica, ainda está em construção dentro das instituições de ensino, em que os atores permanecem divididos entre as questões biológicas e psicossociais dos transtornos mentais, o que marca a formação dos profissionais da área de saúde mental (Pereira et al., 2015). Com isso, se torna cada vez mais necessário pensar e discutir a respeito das novas abordagens de saúde mental dentro dos cursos de saúde.

Entre as novas abordagens em saúde mental, há o Movimento Internacional de Ouvidores de Vozes, que foi fundado em 1987, na Holanda, pela ouvidora Patsy Hage e seu psiquiatra Marius Romme. As vozes que Patsy escutava eram de teor negativo e os medicamentos prescritos não apresentavam resultados benéficos, o que a levou a buscar outras formas de lidar com essa experiência (Escher \& Romme, 2012).

Após algumas intervenções, Marius Romme e Sandra Escher montaram os primeiros grupos de ouvidores de vozes na Holanda, com o objetivo de que eles pudessem compartilhar suas experiências (Escher \& Romme, 2012). Na perspectiva do movimento, ouvir vozes que os outros não ouvem é tomado como uma experiência humana que, por si só, não pode ser considerada um sintoma de doença psiquiátrica. O Movimento de Ouvidores de Vozes consiste em mais uma estratégia a ser colocada na terapêutica de pessoas que não respondem bem aos tratamentos prescritos. Nesse sentido, o objetivo 
é produzir estratégias de enfrentamento para lidar com as vozes no cotidiano, ao invés de procurar aniquilá-las (Egito \& Silva, 2019).

Porém, o modelo biomédico categoriza a presença das vozes como sinais e sintomas relacionados a esquizofrenia, depressão maior, uso de substâncias, entre outras condições. As vozes, nessa perspectiva, estão relacionadas a uma condição patológica que precisa ser solucionada, e não a uma experiência humana, como apontado pela abordagem dos ouvidores de vozes (Corradi-Webster, Leão, \& Rufato, 2018).

O cuidado em saúde mental leva em conta o sujeito em sua integralidade, seu contexto familiar e comunitário, aproximando "o cuidado que se tem e o cuidado que se almeja ter em saúde mental" (Santin \& Klafke, 2011, p. 147). Nessa abordagem, a família é vista como "a base de sustentação e tem papel terapêutico, o que implica ajuda, apoio emocional e geração de afeto, de segurança, de promoção de desenvolvimento, de estabilidade e de conforto" (Silva, Quadros, Laroque, Lima, \& Coimbra, 2010, p. 247).

Antes da Reforma Psiquiátrica, existiam diferentes compreensões em relação à família, que, de certa forma, contribuíram para sua culpabilização e seu afastamento do sujeito com sofrimento psíquico durante o cuidado em saúde mental (Rosa, 2005). Com a reforma, a família passou a ter um papel fundamental nesse tratamento, tornando-se responsável pelo cuidado de seu familiar em tempo integral, além de ser importante no processo de retomada de uma vida em sociedade, constituindo-se num elo com a vida em comunidade.

Estudos mostram que a aproximação do sujeito com sofrimento psíquico de sua família gera inúmeros benefícios ao tratamento, no entanto, há que se atentar ao fato de que o cuidado de uma pessoa com sofrimento psíquico pode gerar sobrecarga para os familiares, o que torna indispensável um suporte especializado a esses cuidadores (Costa, Pessôa, Soares, \& Rocha, 2014).

Na literatura brasileira, a temática dos ouvidores de vozes tem sido desenvolvida em estudos relacionados aos conteúdos, sentidos e relações dos ouvidores com as vozes, além de identificar os possíveis traumas que levaram à escuta de vozes e os tratamentos preconizados. Contudo, pesquisas relacionadas aos familiares cuidadores de pessoas que ouvem vozes ainda são escassas. Nesse sentido, este estudo leva em conta a importância de se olhar para as relações interpessoais dos ouvidores de vozes, em especial para as relações que se produzem no contexto familiar, entendendo esse suporte como um diferencial no tratamento (Baker, 2016). Ancorado numa perspectiva psicossocial, frente aos desafios da reinserção social e da composição de estratégias de cuidado em liberdade, este artigo tem por objetivo analisar as narrativas dos familiares de ouvidores de vozes sobre suas experiências como cuidadores.

\section{Método}

O percurso metodológico abrangeu a escuta, o registro e a análise das narrativas sobre os efeitos das experiências de familiares no cuidado de pessoas que ouvem vozes. A produção dos dados se deu através da realização de entrevistas narrativas (Jovchelovitch \& Bauer, 2008) com familiares/cuidadores de integrantes do grupo de ouvidores de vozes de um Caps da cidade de Pelotas.

Primeiramente, ocorreu a inserção da pesquisadora no grupo de ouvidores de vozes, que se reunia a cada 15 dias e foi acompanhado pela pesquisadora durante quatro meses consecutivos. Para a realização do estudo, foram identificados dez integrantes assíduos no grupo, aos quais foram apresentados os objetivos da pesquisa e solicitadas indicações de cuidadores que pudessem participar do estudo. Três ouvidores não se sentiram à vontade para indicar um familiar para a pesquisa. Após o consentimento dos demais, foram realizados contatos telefônicos com os cuidadores para agendamento da entrevista.

Foram realizadas sete entrevistas, com seis mulheres e um homem, todos familiares consanguíneos de ouvidores de vozes. Como critérios de inclusão no estudo, foram utilizados: ser familiar/cuidador de integrante do grupo de "Ouvidores de vozes" de um Caps da cidade Pelotas e ter sido indicado pelo ouvidor a participar do estudo.

As entrevistas foram gravadas e transcritas, e o material produzido foi analisado a partir da análise temática (Braun \& Clarke, 2006). No entanto, duas participantes não se sentiram à vontade para gravar as entrevistas e suas narrativas foram escritas em um diário de campo. A partir desta proposta de análise, procurou-se identificar os temas geradores e representativos das narrativas dos familiares.

Esta pesquisa foi aprovada pelo Comitê de Ética em Pesquisa na área da Saúde (Cepas) sob parecer $\mathrm{n}^{\mathrm{o}} 3.936 .821$.

\section{Resultados/discussão}

A partir da análise das entrevistas, foram produzidos três eixos temáticos: (1) experiência de ouvir vozes e necessidade de cuidado; (2) família: práticas de cuidado; e (3) estratégias terapêuticas: tecendo redes de cuidado compartilhadas em saúde mental. 
Tabela 1. Dados sociodemográficos dos familiares/cuidadores de ouvidores de vozes

\begin{tabular}{ccccc}
\hline Nome & Idade & Estado civil & Grau de parentesco & Trabalha atualmente \\
\hline Ana & 63 anos & Divorciada & Mãe & Aposentada \\
Beatriz & 49 anos & Viúva & Mãe & Desempregada \\
Carmen & 56 anos & Casada & Mãe & Aposentada \\
Daniela & 20 anos & Solteira & Filha & Trabalha \\
Eduardo & 37 anos & Casada & Filho & Trabalha \\
Fernanda & 34 anos & Divorciada & Filha & Trabalha \\
Gabriela & 25 anos & Solteira & Sobrinha & Desempregada \\
\hline
\end{tabular}

Fonte: Elaboração própria.

\section{Experiência de ouvir vozes e necessidade de cuidado}

Muitos dos cuidadores relataram que o início do sofrimento psíquico se manifestou "como uma depressão" e que, aos poucos, outros diagnósticos foram recebidos, como a notícia da esquizofrenia, que gerou preocupação, já que essa patologia carrega um forte estigma social. Tal diagnóstico desencadeou, na percepção dos cuidadores, maior dificuldade em aceitar a mudança e, depois, em organizar estratégias de convivência com o familiar em casa.

As mudanças no comportamento, causadas por alucinações auditivas e visuais, costumam gerar sofrimentos e preocupações aos cuidadores (Carvalho, Sousa, Pinho, Fernandes, \& Oliveira, 2017), como evidenciam os relatos de Carmen, mãe de um ouvidor, e de Fernanda, filha de uma ouvidora:

Foi detectado que era esquizofrenia, mas o começo foi uma depressão. E aquilo para mim foi um susto, não sabia, não conhecia a doença. Foi horrivel. (Carmen)

Começou com uma depressão. Mas, com o tempo, foi escutando vozes, escutando que estavam mandando ela fazer coisas. Tinha uns surtos de noite, de dia. Era agressiva, não reconhecia a gente, principalmente de noite. Não tomava os remédios, escondia os remédios, e ai foi piorando. (Fernanda)

Da mesma forma, o diagnóstico de esquizofrenia também pode estar associado a sentimentos de culpa (Giacon \& Galera, 2013), como mostra a fala de Ana sobre sua experiência com a filha:

Ah, desde a primeira vez que ela tentou suicídio foi muito dificil. Mas como, o que eu errei? Por que ela é tão diferente, por causa que a outra (irmã) é descolada, bem diferente, é normal e ela assim sempre com dificuldade. Não tinha diálogo, muito fechada. (Ana)
Os cuidadores deste estudo passaram por um período preenchido por angústias, medos e novas adaptações em razão do adoecimento de seu familiar. Concomitantemente, buscaram frequentemente explicações para a situação que vivenciavam. Por isso é importante ter em vista que os cuidadores também necessitam de cuidado, para que sentimentos, como culpa, cansaço e solidão, também não os levem a adoecer (Ferreira, Sampaio, Oliveira, \& Gomes, 2019).

Em muitos casos, a experiência auditiva é transitória e pode desaparecer com o tempo (van Os, Linscott, MyinGermeys, Delespaul, \& Krabbendam, 2009), o que é corroborado por um estudo que acompanhou, durante cinco anos, 337 crianças que escutavam vozes, com idades entre 7 e 8 anos, com o objetivo de medir possíveis fatores de risco, constatando em seus resultados que a maioria $(76 \%)$ delas deixou de escutar vozes quando atingiu a faixa etária de 12-13 anos (Bartels-Velthuis, Willige, Jenner, van Os, \& Wiersma, 2011). Mas o que fazer quando os familiares, depois de anos, ainda escutam vozes, mesmo com histórico de uso regular de psicotrópicos?

Entre as orientações do Movimento Internacional de Ouvidores de Vozes, constam a abertura de um diálogo com as vozes que escutam; tentar realizar uma seleção das vozes positivas e somente ouvir e conversar com elas; tentar marcar encontros com as vozes, para que elas não apareçam em qualquer horário do dia; quando escutam algo que não sabem diferenciar se é realidade ou não, sugere-se que o ouvidor pergunte a uma pessoa próxima se ela também escutou (Baker, 2016). Essas estratégias de enfrentamento são importantes para que o ouvidor de vozes possa encontrar um significado para as vozes, além de auxiliar na aceitação dessa experiência.

O contato dos cuidadores com essas estratégias possibilita a compreensão da experiência de seu familiar de outro modo. Beatriz, mãe de uma ouvidora, disse que foi a primeira pessoa para a qual sua filha contou que escutava vozes. Além disso, comentou que sabe que as vozes são concretas, porque desde que sua filha começou o tratamento no Caps, começou a perceber a quantidade de pessoas que escutavam vozes, mas reconhece que ainda existe muito preconceito. 
O preconceito com quem escuta vozes é bastante presente e pode estar ligado ao estereótipo de que ouvir vozes é um sinônimo de loucura. Muitas pessoas que escutam vozes têm medo de falar abertamente sobre isso, pois temem ser encaminhadas para o psiquiatra e/ou internações, além de receberem aumento de doses no tratamento medicamentoso (Kantorski, Andrade, \& Cardano, 2017).

A proximidade dos familiares com o conteúdo das vozes dos ouvidores nem sempre se mostra uma tarefa fácil, sobretudo quando apresentam conteúdo negativo. Fernanda comentou que as vozes que sua mãe escutava mandavam que ela machucasse a si mesma e aos outros: "foi complicado, estranho, porque ela nunca tinha falado nada e principalmente quando ela disse que era para matar a neta, que é um bebezinho".

Para o Movimento, as vozes podem se apresentar de diferentes formas, como auditiva (sons, ruídos e músicas), sensorial e visual. Além disso, elas podem conter conteúdos positivos, negativos ou neutros, como vozes de chamado (Couto \& Kantorski, 2020). Um estudo realizado com oito ouvidores de vozes no Brasil apontou que aqueles que realizavam algum tipo de acompanhamento em serviços de saúde mental demonstraram ter mais relações negativas do que positivas com as vozes (Kantorski, Souza, Farias, Santos, \& Couto, 2018), o que vai ao encontro dos relatos dos participantes deste estudo acerca das vozes de seus familiares.

Eduardo, por sua vez, revelou tranquilidade ao lidar com as vozes da mãe, ainda que apresente algumas preocupações:

Eu não me assusto tanto porque eu leio bastante, então não é nenhum absurdo quando uma pessoa fala que escuta vozes. Na minha cabeça eu penso normal não é, mas tipo, tá com algum conflito dentro do cérebro, não sei a palavra certa, mas tem que acertar isso daí, não é normal tá isso ali, tem que tratar. (Eduardo)

No decorrer do estudo, as narrativas dos cuidadores trouxeram vivências associadas ao sofrimento, em razão de muitas vezes não conseguirem realizar um diálogo com seus familiares a respeito das vozes. Cabe aos serviços de saúde escutar e acolher todas essas dificuldades apresentadas pelos cuidadores, para que se possa pensar em estratégias de intervenção que os auxiliem durante o tratamento de seus familiares.

\section{Família: práticas de cuidado}

As narrativas expressam sobrecarga física e emocional associadas ao convívio próximo com a pessoa em sofrimento psíquico, como pode ser acompanhado na fala de Daniela: "Eu tenho três filhos: meu filho, minha mãe e meu irmão". Em sua rotina, Daniela cuida de sua casa e auxilia na residência de sua mãe. Ela relembra que a mãe a ajudava no cuidado de seu filho de três anos, porém, com o agravamento da doença, não teve mais condições de continuar nessa atividade, fazendo com que Daniela precisasse mudar seu horário de trabalho e se adaptar à nova rotina.

Da mesma maneira que Daniela, Fernanda também relata ser a principal responsável pela mãe: "Eu sou a principal [cuidadora]. Eu que levo para tudo. Muito dificil a minha irmã levar. Mas eu que levo para tudo, eu cuido de médico... O que tiver que fazer para ela assim, eu faço".

Assim como evidenciado em outros estudos, a responsabilização pelo cuidado de pessoas em sofrimento psíquico na família ao longo da história foi atribuída às mulheres (Nolasco, Bandeira, Oliveira, \& Vidal, 2014; Reis, Dahl, Barbosa, Teixeira, \& Delgado, 2016). É delegado às mulheres o cuidado dos filhos, dos idosos e dos deficientes, de maneira que, somado às atividades laborais fora do domicílio, ocorre um acúmulo de tarefas e, consequentemente, sobrecarga física e psíquica (Meira, Reis, Gonçalves, Rodrigues, \& Philipp, 2017).

Além disso, a convivência familiar com a pessoa em sofrimento psíquico pode desencadear problemas de saúde aos cuidadores e ocasionar sentimentos como estresse, desânimo e medo, bem como quadros mais graves, como cardiopatias e transtornos mentais (Carvalho et al., 2017). Duas entrevistadas relataram realizar algum tipo de acompanhamento por conta da sobrecarga de cuidados que dispensam aos seus familiares. Beatriz conta que decidiu procurar atendimento e começou a frequentar o Caps. Já Ana relatou aderir a tratamentos esporádicos: "quando ela passa muito mal, eu fico muito irritada e eu acabo com depressão. Ai faço tratamento três meses e paro. Agora esse ano passado, eu fiz um ano de tratamento com Fluoxetina, mas parei".

Gabriela relata que sua tia é bastante independente e que a procura sempre que necessita de alguma ajuda: "Ela me procura muito, ela me diz: tem uma palestra tal em tal lugar, vai abrir vaga pra estágio. Ela tem muito essa questão de ajudar". Em contrapartida, Daniela contou que sua mãe é bastante dependente, "seja para escolher uma cor de esmalte, uma roupa ou até decisões mais importantes, tudo tem que ter a minha opinião".

A partir das narrativas, evidenciou-se que o cuidado com a saúde mental pode modificar a dinâmica familiar, uma vez que se incluem no dia a dia: idas ao Caps, ao médico, à unidade básica de saúde, entre outras atividades necessárias ao tratamento da pessoa em sofrimento psíquico.

Dois participantes da pesquisa relataram que seu familiar é independente, de forma que consegue realizar essas atividades sem a presença de um cuidador. Porém, outros cuidadores comentaram a necessidade de realizar esse acompanhamento de maneira mais presente, com o intuito de proteger o familiar, como é o caso de Beatriz, que disse não se sentir tranquila em deixar sua filha em casa sozinha, pois a filha escuta vozes que a mandam atentar contra a própria vida. Para Fernanda, o cuidado também deve ser realizado mais de perto: 
Tem que cuidar em todos os sentidos né, porque ela não anda sozinha. Assim como ela já tentou várias vezes o suicídio, eu que medico ela... Cuida de médico, cuida de tudo, se come ou se não come, isso tem que estar sempre atentinha. (Fernanda)

Segundo estudo de Sant'Ana, Pereira, Borenstein e Silva (2011), a responsabilidade de cuidar, somada ao fato de se tratar um familiar próximo, tende a demandar desse cuidador disponibilidade e paciência, já que, por vezes, ele é o único familiar que se dispõe a realizar essa atividade. Um dos desafios está em equilibrar o exercício de cuidado para que não se traduza em tutela, comprometendo o processo de autonomia e participação no tratamento (Ramos, Calais, \& Zotesso, 2019).

Durante as entrevistas, ficou evidente a falta de tempo para os cuidadores se dedicarem a outras atividades além da atenção a seus familiares, muitas vezes por serem os únicos a assumirem essa responsabilidade. Nesta pesquisa, cinco dos entrevistados relataram que não contam com outra pessoa para ajudar nos cuidados de seu familiar. Carmen se aposentou recentemente, e desde então tem ficado em casa com o filho e o marido. Em relação a ter tempo para lazer, ela relatou: "Tá difícil". Por outro lado, Fernanda contou que atualmente busca se organizar para ter tempo para si e relembra que houve uma época em que deixava de fazer diversas atividades por conta do cuidado com a mãe: "Agora eu me permito mais, porque teve uma época que era só em função dela... Mas já deixei de fazer coisas, mas agora não deixo mais".

Dentre os sete cuidadores entrevistados, os três que moravam na mesma casa com o familiar em sofrimento psíquico relataram não terem muito tempo para si ou para lazer. Percebe-se que o fato de lidarem mais de perto com o familiar em sofrimento psíquico demanda maior responsabilidade do cuidador, que, muitas vezes, deixa de lado seu cuidado pessoal em razão das demandas do familiar. Em contraponto a isso, outros participantes disseram que conseguem conciliar esse cuidado e o tempo dedicado a si mesmos. Esse fato pode decorrer do quadro de maior dependência ou independência do ouvidor, ou, também, do modo como é percebido pelos familiares.

Ao longo da pesquisa, os participantes relataram que realizavam o cuidado de seus familiares de diferentes formas, como: acompanhando-os em consultas médicas e no Caps, auxiliando-os na rotina de casa e os incentivando a realizar outras atividades que fujam do contexto da "doença". Por vezes, o cuidado "excessivo" gerou um estado de sobrecarga em alguns dos entrevistados, que, além de lidarem com suas tarefas e seus compromissos, responsabilizavam-se pelo cumprimento de outras tarefas de seu familiar em sofrimento psíquico, ocasionando sofrimento e adoecimento a esses cuidadores. Compreende-se que o equilíbrio entre as tarefas realizadas não é simples, mas, ao encontrarem apoio para dividir suas angústias, seus medos e suas preocupações, os familiares têm mais condições de olhar para si e de buscar a realização de práticas de autocuidado, atividades que lhes são prazerosas e que promovem saúde mental.

\section{Estratégias terapêuticas: tecendo redes de cuidado compartilhadas em saúde mental}

Neste eixo temático, serão abordadas reflexões sobre o compartilhamento do cuidado, que ocorre no Caps, assim como a oferta de cuidado prestada pelo projeto "Ouvidores de vozes - novas abordagens em saúde mental", executado pela Universidade Federal de Pelotas (UFPel). O Caps oferta, dentre suas atividades, o grupo de ouvidores de vozes, que é fruto de uma parceria entre esse serviço e a UFPel. O grupo se reúne nesse local desde o ano de 2017 e são convidados a participar todos os ouvidores de vozes desse serviço.

Destaca-se que os Caps têm importante papel na rede de assistência à saúde mental, pois se configuram como um espaço para o desenvolvimento de autonomia, cuidado e inclusão social. Porém, deve-se atentar para que esses serviços não realizem práticas associadas à tutela e à cronificação dos usuários (Costa, Figueiró, \& Freire, 2014), reiterando, assim, práticas manicomiais que limitam e estigmatizam a atuação da pessoa no cotidiano da cidade.

Dessa forma, a proposta de trabalho dos Caps objetiva a reabilitação psicossocial de seus usuários, tornando-se importante que os cuidadores participem do processo. Neste sentido, os entrevistados foram questionados a respeito do tratamento de seu familiar no Caps e sua relação com os profissionais desse serviço.

Ana contou que sempre que tem alguma dúvida ou que percebe algo que julga errado, vai até o Caps e conversa com algum profissional do dispositivo. Relatou que se sente muito bem no serviço devido ao acolhimento:

Sempre com os problemas que eu tive mais grave com a [filha], sempre me ajudaram. Minhas dificuldades, qualquer problema de saúde da [filha], eles sempre me ajudaram, não tem queixa. Estão sempre à disposição, sempre abertos à conversa e ao diálogo. (Ana)

Nesse contexto, entende-se que os grupos de familiares são fundamentais para que haja maior contato entre o cuidador e o serviço de saúde, visto que as reuniões contribuem para a troca de experiências, em que os cuidadores podem escutar histórias de vida semelhantes ou diferentes das suas, podem expor suas dificuldades, sentimentos e angústias, assim como receber apoio, tanto dos demais participantes quanto da equipe do serviço (Machado \& Rodrigues, 2017).

Fernanda contou que sua mãe passou por diversas internações, tentativas de suicídio e depressão. Após a entrada no Caps e o início do acompanhamento terapêutico, percebeu uma melhora no estado de saúde da mãe, que passou a ter maior participação nas atividades do serviço: "Desde que ela entrou no Caps, ela não se 
internou mais. Acho que faz um ano e pouco já'. Em relação a esse assunto, Duarte e Ferreira Neto (2016) realizaram um estudo com o objetivo de investigar as modificações de vida experienciadas pelos cuidadores de pessoas em sofrimento psíquico, e trouxeram em seus resultados que "as novas modalidades de tratamento substitutivas à internação psiquiátrica foram bem acolhidas pelos familiares responsáveis pelo cuidado" (p. 483).

No entanto alguns cuidadores relataram um descontentamento em relação ao Caps. Daniela comentou não gostar do atendimento realizado no serviço, pois, nas vezes em que foi até lá para conversar sobre a mãe, não se sentiu compreendida pelos profissionais. Além disso, expressou que o serviço deveria incluir um tratamento mais compreensivo com as pessoas em sofrimento psíquico, sem julgamentos e com espaços de escuta mais acolhedores.

Para Beatriz, o tratamento da filha no Caps não está surtindo efeito, já que sua filha toma uma grande quantidade de medicação e continua escutando as vozes. Acerca do tratamento de sua mãe no Caps, Eduardo contou que percebeu uma melhora gradativa, pois, num primeiro momento, o tratamento parecia estar muito estagnado e não estar surtindo "efeito", mas evoluiu aos poucos.

Falou só coisa boa aqui do pessoal. Eu acho que ela sente que o pessoal que está aqui tá para ajudar, entendeu, e é uma pressão, é sem verba, tem que fazer mágica, então ela sabe do esforço que o profissional que trabalha aqui faz para ver o bem-estar dela, nem que seja um pouquinho. (Eduardo)

Ainda em relação ao Caps, é importante destacar a história e a participação da tia de Gabriela na rede de saúde mental. A ouvidora de vozes possui uma mala, na qual compilou diversos materiais coletados por ela relacionados a eventos, notícias, fotos e acontecimentos na rede de saúde mental do município e, a partir disso, foi produzido um livro, em que ela contou sua história de vida:

Muita coisa eu soube da minha tia através da faculdade... Sobre a mala, eu sabia que ela tinha uma mala com fotos, nunca soube o que tinha. Assim, nós parentes, a gente não sabia e dai eu sei que uma vez encontrei ela na faculdade e ela ia apresentar a mala pra um curso e dai eu fiquei sabendo o que tinha na mala. (Gabriela)

Segundo o Movimento de Ouvidores, o fato de escutar vozes por si só não seria um motivo para fechar um diagnóstico de esquizofrenia. Além disso, salienta que a escolha de se submeter a tratamento medicamentoso ou não deve ser feita em conjunto com o ouvidor (Romme \& Escher, 2000), visto que estudo mostra que há uma proporção significativa (30\%) de ouvidores que continuaram com a experiência de ouvir vozes a despeito de tomarem altas doses de antipsicóticos (Curson et al., 1985). De forma semelhante, durante as narrativas, grande parte dos cuidadores relatou que seus familiares tomam antipsicóticos em consequência das vozes e seguem ouvindo-as.

Na perspectiva do Movimento dos Ouvidores, não se espera uma "melhora" por parte do ouvidor, pois as vozes não são entendidas como doença, e, consequentemente, não se busca uma "cura", mas sim ajudar o ouvidor a conviver com elas. Em contrapartida, os Caps trabalham com diagnósticos, pois entendem as vozes como um sintoma que precisa ser eliminado. A proposta do Movimento de Ouvidores ampara-se nos dados estatísticos que mostram que a experiência de escutar vozes não é compartilhada apenas por pessoas que fazem uso dos serviços de saúde mental, visto que existem indivíduos que ouvem vozes e que não possuem nenhum diagnóstico psiquiátrico e que não estão realizando nenhum tratamento médico por conta delas (Eaton, Romanoski, Anthony, \& Nestadt, 1991; Johns \& van Os, 2001).

Esse dado é corroborado pelo estudo de Romme e Escher (1989), no qual foram realizadas entrevistas com 350 ouvidores de vozes na Holanda, dos quais um terço declarou nunca ter realizado tratamento em serviços psiquiátricos (Romme \& Escher, 1989), bem como pelo estudo de Tien (1991), no qual foram analisadas 18.572 entrevistas com pessoas da população em geral e constatou-se que $10 \%$ dos homens e $15 \%$ das mulheres escutavam ou já tinham escutado vozes em algum período da vida, mostrando ainda que as proporções de vozes que não causam sofrimento ou outros comprometimentos foram bem maiores do que aquelas associadas a comprometimento das atividades do dia a dia.

O curso de Enfermagem da UFPel tem realizado diversas atividades em prol da saúde mental na cidade de Pelotas, uma das quais é o grupo de ouvidores de vozes, fruto de sua parceria com um Caps do município. Esse grupo tem o objetivo de ofertar um espaço seguro de trocas de experiências sobre as vozes, além de promover o autoempoderamento e a independência desses sujeitos.

Contudo, nas narrativas dos cuidadores, foi possível perceber que os ouvidores não comentavam sobre o grupo com seus familiares. Daniela relatou que conhecia pouco sobre a abordagem dos ouvidores de vozes: "eu acho que eles tentam ajudar". Segundo a participante, sua mãe não comenta com ela a respeito dos grupos.

Beatriz relatou que a filha nunca comentou sobre o que acontece nos encontros. A mãe mencionou que os profissionais do grupo incentivaram sua filha a escrever sobre as vozes em um diário, porém, a menina nunca quis compartilhar com ela o conteúdo desse material. A escrita de um diário sobre as vozes é uma das estratégias de enfrentamento utilizadas pelos ouvidores, visto que, através da escrita, as pessoas que escutam vozes podem encontrar significados e conhecer mais sobre essa experiência (Kantorski et al., 2017). Portanto, quando os familiares dispõem de mais suporte e esclarecimento a respeito das vozes, para além do modelo biomédico, eles podem se tornar mais próximos para escutar e ajudar os ouvidores. 
As pessoas que ouvem vozes relatam que a rede de apoio é importante para o seu tratamento. Contudo, há poucos materiais e informações a respeito das novas abordagens para lidar com as vozes disponíveis aos familiares. Para esses ouvidores de vozes, é fundamental que seus amigos e familiares estejam cientes de possíveis causas e significados de ouvir vozes para auxiliá-los no tratamento (Baker, 2016).

No presente estudo, alguns cuidadores relataram que passaram a conhecer mais sobre a abordagem dos ouvidores de vozes no grupo que seu familiar participa no Caps. Fernanda comentou que sabia que existem pessoas que escutavam vozes, porém, não tinha muito conhecimento:

É muito bom para ela ver que não é só ela né. Principalmente porque o pessoal fica achando que é anormal... Aqui tem um monte de gente de diferentes idades, tem gente bem nova. É bom para ela isso, pra ela ver que não é só com ela. Que é uma ajuda, que ajudam a entender o quê, o que fazer quando tá escutando. (Fernanda)

O grupo é um espaço de suporte e reflexão que proporciona aos ouvidores o desenvolvimento de um senso mais crítico acerca de sua experiência. Além disso, torna-se uma potente ferramenta de rede de apoio para que as pessoas se sintam acolhidas e compreendidas.

Acerca disso, Carmen contou que seu filho é muito reservado e não gosta de falar sobre as atividades de que participa no Caps, nem sobre as vozes que escuta. Mas acredita que o grupo tem o ajudado por meio de conselhos e acolhimento:

Eu acho que aconselham ele, não sei. Tentam saber o que tá acontecendo na mente dele, para ajudar. Para ele sair desse surto. A gente tem que ouvir palavra de alguém para mudar, né. E é bom ele vir para ouvir. (Carmen)

Já Gabriela conta que conheceu a abordagem dos ouvidores em uma palestra sobre saúde mental em sua cidade, antes mesmo de saber que sua tia escutava vozes:

Quando eu conheci, eu tipo fiquei assim espantada, porque é bem novo para mim. Porque geralmente quando a gente acha que escuta vozes, a gente já pensa em dar um nome, pensa em algum diagnóstico... Tá enxergando coisas é esquizofrênico ou tá escutando vozes, leva num centro espirita, porque tá um espirito falando com a pessoa... Eu acho que tinha que ser uma coisa bem mais discutida, porque as pessoas sofrem com isso, porque não se abrem com as pessoas, sentem medo ou se automedicam. (Gabriela)

Em decorrência disso, estimula-se que os grupos sejam realizados fora dos serviços de saúde, para que, assim, não sejam associados a ideias de doença ou tratamento, encorajando um maior número de pessoas a participar (Fernandes \& Zanello, 2018). Enfatiza-se a necessidade de ofertar espaços, debates e construções a respeito da abordagem dos ouvidores de vozes dentro da rede de saúde mental, para que, com isso, tanto os usuários e seus familiares quanto a população em geral possam adquirir ferramentas para desconstruir os estereótipos que perpassam a experiência de ouvir vozes.

\section{Considerações finais}

O presente estudo buscou conhecer as narrativas de familiares de pessoas que escutam vozes sobre suas experiências como cuidadores. A partir da reforma psiquiátrica, os cuidados em tempo integral com a pessoa em sofrimento psíquico foram delegados aos familiares, que precisam, muitas vezes, reorganizar seu dia a dia em função desse cuidado. Por se tratar de uma temática nova no cenário brasileiro, ainda existem poucos estudos sobre ouvidores de vozes, principalmente no âmbito familiar.

No cotidiano, o convívio e as práticas de cuidado nem sempre são tarefas fáceis. Tanto a negligência quanto o excesso de cuidado podem gerar complicações para os familiares cuidadores, bem como para as pessoas em sofrimento psíquico, pois o excesso pode trazer uma sobrecarga de cuidados para o familiar - que assume uma posição de responsável direto pelo ouvidor e deixa seu autocuidado em segundo plano -e perda de autonomia por parte do ouvidor, em função da dependência de cuidados realizados por outrem. Portanto é fundamental que se busque um equilíbrio entre a importância do acompanhamento do familiar cuidador e a autonomia da pessoa com sofrimento psíquico, para que o acompanhamento não se torne prejudicial para ambos. Esse auxílio pode ser realizado através dos serviços da rede de saúde mental.

O Movimento de Ouvidores de Vozes enfatiza que a escuta de vozes precisa ser vista como uma experiência do ser humano e fundamenta sua intervenção através da desmistificação dessa escuta, promovendo oportunidades para que os ouvidores signifiquem as vozes e adquiram controle de sua experiência. Porém é importante relembrar que a escuta das vozes, do ponto de vista biomédico, ainda é tratada como sinônimo de loucura, ligada a sinais e sintomas de doenças, principalmente a esquizofrenia. Durante as entrevistas, percebeu-se que os cuidadores apresentaram suas falas guiadas por um viés mais biomédico, expressando distinção entre o que seria "normal" ou não ao se referirem ao comportamento de seu familiar em sofrimento psíquico. Além disso, pode-se observar a falta de informações dos cuidadores sobre a temática dos ouvidores de vozes e seu consequente desconhecimento sobre as principais estratégias para o enfrentamento delas. Isso pode ser resultado do fato de o grupo de ouvidores estar vinculado ao Caps e da forma como atua quanto à escuta de vozes.

Apesar de o Caps ser um serviço com o objetivo de reabilitação psicossocial da pessoa em sofrimento psíquico, ele ainda está muito ligado ao modelo biomédico, pois oferece como principal forma de tratamento o uso de 
medicamentos, motivo pelo qual é visto pela sociedade como uma continuação dos antigos hospitais psiquiátricos, nos quais o foco era a doença, e não o sujeito. Esse tipo de visão contribui para a perpetuação dos preconceitos e estigmas associados às pessoas que utilizam o serviço. Desse modo, evidencia-se a importância de que o Caps, em conjunto com o grupo de ouvidores de vozes, estabeleça estratégias de disseminação do conhecimento a respeito da temática. Em prol do fortalecimento de estratégias para que esses ouvidores sejam reinseridos na vida da cidade, torna-se necessário que não só os familiares, mas a sociedade como um todo se conscientize e colabore para que o cuidado em liberdade seja cada vez mais uma realidade cotidiana.

\section{Mental health care: narratives of family members of voice hearers}

Abstract:Considering the challenges of social reintegration and the composition of care strategies in a context of liberty, this study aims to analyze the narratives of family members of voice hearers regarding their experiences as caregivers from a psychosocial perspective. Narrative interviews were conducted with family members of individuals attending a group of voice hearers at a Psychosocial Care Center in the city of Pelotas, Rio Grande do Sul, Brazil. Three thematic axes were obtained from the thematic analysis of interview data: (1) experience of hearing voices and the need for care; (2) family: care practices; and (3) therapeutic strategies: weaving care networks in mental health. Caregivers report difficulties in living with family members who hear voices, care-related work overload, and challenges faced in daily life. In this context, the results stress the importance of mutual aid groups in supporting caregivers.

Keywords: family, caregivers, voice hearers, mental health.

\section{Soins de santé mentale : récits des familles des entendeurs de voix}

Résumé : Face aux défis de la réinsertion sociale et de la constitution des stratégies de soins dans un contexte de liberté, cette étude analyse les récits des familles des entendeurs sur leurs expériences en tant que soignants de la perspective psychosociale. On a mené des entretiens narratifs avec des membres de la famille de participants à un groupe d'entendeurs de voix dans un Centre de soins psychosociaux de la ville de Pelotas, Rio Grande do Sul, au Brésil. De l'analyse thématique se sont issues trois axes thématiques: (1) l'expérience de l'entente des voix et le besoin de soins; (2) la famille : pratiques de soins ; et (3) les stratégies thérapeutiques : tisser de réseaux de soins partagés en santé mentale. Les récits des soignants signalent de difficultés à vivre avec des membres de la famille qui entendent des voix, de la surcharge de travail liée aux soins et des défis à relever dans la vie quotidienne. L'article souligne l'importance des espaces de groupes d'entraide qui peuvent aider les soignants.

Mots-clés : famille, soignants, entendeurs de voix, santé mentale.

\section{Cuidado en salud mental: relatos de familiares de oyentes de voces}

Resumen: A partir de una perspectiva psicosocial y teniendo en cuenta los desafíos de la reinserción social y la composición de las estrategias de cuidado en libertad, este estudio tiene como objetivo analizar los relatos de familiares de los oyentes de voces sobre sus vivencias como cuidadores. Se realizaron entrevistas a familiares de oyentes de voces de un Centro de Atención Psicosocial de la ciudad de Pelotas, en Rio Grande do Sul, Brasil. A partir del análisis temático se produjeron tres ejes temáticos: (1) experiencia de escuchar voces y necesidad de cuidado; (2) familia: prácticas de cuidado; y (3) estrategias terapéuticas: tejiendo redes de cuidado compartidas en salud mental. Los cuidadores relatan las dificultades para convivir con familiares que escuchan voces, la sobrecarga laboral relacionada con el cuidado y los desafíos que enfrentan en la vida diaria. Se destaca la importancia de los espacios grupales de ayuda mutua que pueden ayudar a los cuidadores.

Palabras-clave: familia, cuidadores, oyentes de voz, salud mental.

\section{Referências}

Baker, P. (2016). Abordagem de ouvir vozes: treinamento Brasil (L. F. Lansky, Trad.). São Paulo, SP: Cenat.

Bartels-Velthuis, A. A., Willige, G., Jenner, J. A., van Os, J., \& Wiersma, D. (2011). Course of auditory vocal hallucinations in childhood: 5-year follow-up study. The British Journal of Psychiatry, 199(4), 296302. doi: 10.1192/bjp.bp.110.086918

Braun, V., \& Clarke, V. (2006). Using thematic analysis in psychology. Qualitative Research in Psychology, 3(2), 77-101. doi: 10.1191/1478088706qp063oa 
Carvalho, C. M. S., Sousa, D. M. G., Pinho, R. I. A., Fernandes, M. A., \& Oliveira, A. D. S. (2017). Vivências de familiares da pessoa com esquizofrenia. SMAD: Revista Eletrônica Saúde Mental Álcool e Drogas, 13(3), 125131. doi: 10.11606/issn.1806-6976.v13i3p125-131

Corradi-Webster, C. M., Leão, E. A., \& Rufato, L. S. (2019). Colaborando na trajetória de superação em saúde mental: Grupo de Ouvidores de Vozes. Nova Perspectiva Sistêmica, 27(61), 22-34. doi: 10.38034/nps.v27i61.411

Costa, G. M., Pessôa, C. K. L., Soares, C. A., \& Rocha, S. A. M. (2014). A importância da família nas práticas de cuidado no campo da Saúde Mental. Cadernos ESP, 8(1), 41-57.

Costa, M. G. S. G., Figueiró, R. A., \& Freire, F. H. M. A. (2014). O fenômeno da cronificação nos Centros de Atenção Psicossocial: um estudo de caso. Temas em Psicologia, 22(4), 839-851. doi: 10.9788/TP2014.4-13

Couto, M. L. O., \& Kantorski, L. P. (2020). Ouvidores de vozes de um serviço de saúde mental: Características das vozes e estratégias de enfrentamento. Psicologia \& Sociedade, 32, e219779. doi: 10.1590/1807-0310/2020v32219779

Curson, D. A., Barnes, T. R., Bamber, R. W., Platt, S. D., Hirsch, S. R., \& Duffy, J. C. (1985). Long-term depot maintenance of chronic schizophrenic out-patients: the seven year follow-up of the Medical Research Council fluphenazine/placebo trial. III. Relapse postponement or relapse prevention? The implications for long-term outcome. The British Journal of Psychiatry, 146(5), 474480. doi: 10.1192/bjp.146.5.474

Delfini, P. S. S., Sato, M. T., Antoneli, P. P., \& Guimarães, P. O. S. (2009). Parceria entre CAPS e PSF: o desafio da construção de um novo saber. Ciência \& Saúde Coletiva, 14(Suppl. 1), 1483-1492. doi: 10.1590/ S1413-81232009000800021

Duarte, L. G. M. F., \& Ferreira Neto, J. L. (2016). Familiares responsáveis pelo cuidado de pessoa com transtorno mental em um município de pequeno porte. Pesquisas $e$ Práticas Psicossociais, 11(2), 473-488.

Eaton, W., Romanoski, A., Anthony, J., \& Nestadt, G. (1991). Screening for psychosis in the general population with a self-report interview. The Journal of Nervous and Mental Disease, 179(11), 689-693. doi: 10.1097/00005053-199111000-00007

Egito, M. A. T., \& Silva, E. A. (2019). Grupo de ouvidores de vozes no enfretamento de estigmas e preconceitos. Revista do NUFEN, 11(2), 6076. doi: 10.26823/ RevistadoNUFEN.vol11.n02artigo53

Escher S., \& Romme M. (2012). The hearing voices movement. In J. D. Blom, \& I. E. C. Sommer (Eds.), Hallucinations research and practice (pp. 385393). New York: Springer.

Fernandes, H. C. D., \& Zanello, V. (2018). O grupo de ouvidores de vozes: dispositivo de cuidado em saúde mental. Psicologia em Estudo, 23. doi:10.4025/ psicolestud.v23.e39076

Ferreira, T. P. S., Sampaio, J., Oliveira, I. L., \& Gomes, L. B. (2019). A família no cuidado em saúde mental: desafios para a produção de vidas. Saúde em Debate, 43(121), 441-449. doi: 10.1590/0103-1104201912112

Giacon, B. C. C., \& Galera, S. A. F. (2013). Ajustamento familiar após o surgimento da esquizofrenia. Revista Brasileira de Enfermagem, 66(3), 321-326. doi: 10.1590/ S0034-71672013000300003

Johns, L. C., \& van Os, J. (2001). The continuity of psychotic experiences in the general population. Clinical Psychology Review, 21(8), 1125-1141. doi: 10.1016/ s0272-7358(01)00103-9

Jovchelovitch, S., \& Bauer, M. W. (2008). Entrevista narrativa. In M. W. Bauer, \& Gaskell, G. (Orgs.), Pesquisa qualitativa com texto: imagem e som: um manual prático (7a ed., pp. 90-113). Petrópolis, RJ: Vozes.

Kantorski, L. P., \& Andrade, A. P. M. (2017). Assistência psiquiátrica mundo afora: práticas de resistência e garantia de direitos. Cadernos Brasileiros de Saúde Mental, 9(24), 50-72.

Kantorski, L. P., Andrade, A. P. M., \& Cardano, M. (2017). Estratégias, expertise e experiências de ouvir vozes: entrevista com Cristina Contini. Interface Comunicação, Saúde, Educação, 21(63), 1039-1048. doi: 10.1590/1807-57622017.0031

Kantorski, L. P., Souza, T. T., Farias, T. A., Santos, L. H., \& Couto, M. L. O. (2018). Ouvidores de vozes: relações com as vozes e estratégias de enfrentamento [número especial]. Journal of Nursing and Health, 8, 1-8. doi: 10.15210/jonah.v8i0.14121

Lei n. 10.216, de 6 de abril de 2001. (2001). Dispõe sobre a proteção e os direitos das pessoas portadoras de transtornos mentais e redireciona o modelo assistencial em saúde mental. Diário Oficial da União. Recuperado de https://bit.ly/31sIwOd

Machado, B. R., \& Rodrigues, T. (2017). Grupos de familiares em caps II: Gerando reflexões acerca da participação da família no tratamento dos usuários. Disciplinarum Scientia. Série: Ciências Humanas, 18(1), 171-180.

Meira, E. C., Reis, L. A., Gonçalves, L. H. T., Rodrigues, V. P., \& Philipp, R. R. (2017). Vivências de mulheres cuidadoras de pessoas idosas dependentes: orientação de gênero para o cuidado. Escola Anna Nery, 21(2), 1-8. doi: 10.5935/1414-8145.20170046

Mielke, F. B. (2009). O cuidado em saúde mental no Caps no entendimento dos profissionais. Ciência \& Saúde Coletiva, 14(1), 159-164. doi: 10.1590/S141381232009000100021

Mota, V. A., \& Costa, I. M. G. (2017). Relato de experiência de uma psicóloga em um Caps, Mato Grosso, Brasil. Psicologia: Ciência e Profissão, 37(3), 831-841. doi: 10.1590/1982-3703004292016

Nolasco, M., Bandeira, M., Oliveira, M. S., \& Vidal, C. E. L. (2014). Sobrecarga de familiares cuidadores em relação ao diagnóstico de pacientes psiquiátricos. Jornal Brasileiro de Psiquiatria, 63(2), 89-97. doi: 10.1590/00472085000000011

Pereira, A. A., Reinaldo, A. M. S., \& Andrade, D. C. L. (2015). Formação dos enfermeiros em saúde mental 
que atuam na Atenção Primária à Saúde: contribuições teóricas. SANARE, 14(1), 8-14.

Portaria $\mathrm{n}^{\mathrm{o}}$ 336, de 19 de fevereiro de 2002. (2002, 20 de fevereiro). Estabelece que os Centros de Atenção Psicossocial poderão constituir-se nas seguintes modalidades de serviços: CAPS I, CAPS II e CAPS III, definidos por ordem crescente de porte/complexidade e abrangência populacional. Diário Oficial da União.

Ramos, A. C., Calais, S. L., \& Zotesso, M. C. (2019). Convivência do familiar cuidador junto a pessoa com transtorno mental. Contextos Clínicos, 12(1), 282-302. doi: $10.4013 /$ ctc.2019.121.12

Reis, T. L., Dahl, C. M., Barbosa, S. M., Teixeira, M. R., \& Delgado, P. G. G. (2016). Sobrecarga e participação de familiares no cuidado de usuários de Centros de Atenção Psicossocial. Saúde em Debate, 40(109), 70-85. doi: 10.1590/0103-1104201610906

Romme, M., \& Escher, A. (1989). Hearing voices. Schizophrenia Bulletin, 15, 209-216. doi: 10.1093/schbul/15.2.209

Romme, M., \& Escher, S. (2000). Making sense of voices: a guide for mental health professionals working with voice-hearers. London: Mind.

Rosa, L. C. S. (2005). A inclusão da família nos projetos terapêuticos dos serviços de saúde mental. Psicologia em Revista, 11(18), 205-218.
Sant'Ana, M. M., Pereira, V. P., Borenstein, M. S., \& Silva, A. L. (2011). O significado de ser familiar cuidador do portador de transtorno mental. Texto \& Contexto Enfermagem, 20(1), 50-58. doi: 10.1590/S010407072011000100006

Santin, G., \& Klafke, T. E. (2011). A família e o cuidado em saúde mental. Barbaroi, (34), 146-160.

Silva, E. C., Quadros, L. C. M., Laroque, M. F., Lima, Z. G., \& Coimbra, V. C. C. (2010). Inserção da família no cuidado ao portador de transtorno mental. In V. C. C. Coimbra \& L. P. Kantorski (Orgs.), Atenção psicossocial no Sistema Único de Saúde (pp. 245-255). Pelotas, RS: Editora PREC-UFPEL.

Tien, A. Y. (1991). Distribution of hallucinations in the population. Social Psychiatry and Psychiatric Epidemiology, 26(6), 287-292. doi: 10.1007/BF00789221

van Os, J., Linscott, R. J., Myin-Germeys, I., Delespaul, P., \& Krabbendam, L. (2009). A systematic review and metaanalysis of the psychosis continuum: evidence for a psychosis proneness-persistence-impairment model of psychotic disorder. Psychological Medicine, 39(2), 179195. doi: $10.1017 /$ S0033291708003814

Recebido: 11/01/2021 Aprovado: 14/05/2021 